\title{
A phase I study of nedaplatin, pemetrexed and thoracic intensity-modulated radiotherapy for inoperable stage III lung adenocarcinoma
}

Yiyu $\mathrm{Lu}^{1 \dagger}$, Weiguang $\mathrm{Gu}^{1 \dagger}$, Jin Deng ${ }^{2}$, Hua Yang ${ }^{1}$ and Wen Yang ${ }^{1 *}$

\begin{abstract}
Background: Concurrent chemotherapy and radiation is the standard treatment for unresectable stage III Lung adenocarcinoma. However, no optimal concurrent chemotherapeutic regimen has been described. This study aimed to assess concurrent pemetrexed, nedaplatin and thoracic intensity-modulated radiotherapy followed by consolidation pemetrexed/nedaplatin for unresectable Stage IIIA/B lung adenocarcinoma.

Methods: Patients with unresectable stage III lung adenocarcinoma received thoracic intensity-modulated radiotherapy at 60-64 Gy in 30-32 fractions, concurrently with two cycles of $500 \mathrm{mg} / \mathrm{m}^{2}$ pemetrexed, with nedaplatin doses escalating from $60 \mathrm{mg} / \mathrm{m}^{2}$ (level 1) to $70 \mathrm{mg} / \mathrm{m}^{2}$ (level 2) and $80 \mathrm{mg} / \mathrm{m}^{2}$ (level 3). Consolidation consisted of three pemetrexed/nedaplatin $\left(500 \mathrm{mg} / \mathrm{m}^{2}, 60 \mathrm{mg} / \mathrm{m}^{2}\right)$ cycles every 3 weeks after concurrent therapy. The primary objective of the safety was to determine the maximum-tolerated dose (MTD). The secondary endpoints included response rate, PFS and OS.

Results: Fifteen patients were enrolled, including 3, 6 and 6 individuals in the first, second, and third dose levels, respectively. Three cases of dose-limiting toxicities (grade 3 hepatitis, pneumonitis, and grade 4 thrombocytopenia), including one and two patients at levels 2 and 3, respectively, were observed and resulted in discontinued/delayed treatment. Response rates were 86.7 \% (95 \% confidence interval [Cl], 64.2-97.8 \%) and $64.3 \%$ (95 \% Cl, 38.3-85. $4 \%)$ at chemoradiation and treatment completions, respectively. Median OS was 30.0 months (95\% Cl, 16.4-43. 6 months); 2-year OS was $44.0 \%$ (95 \% Cl, 18.7-69.2 \%). Median PFS was 12.0 months (95 \% Cl, 6.9-17.0 months), and the 2-year PFS $27.0 \%$ (95\% Cl, 4.7-49.3\%).

Conclusions: Full dose $500 \mathrm{mg} / \mathrm{m}^{2}$ of pemetrexed and nedaplatin $70 \mathrm{mg} / \mathrm{m}^{2}$ could be used safely with thoracic intensity-modulated radiotherapy for inoperable stage III lung adenocarcinoma. Further evaluation of stage III lung adenocarcinoma management is warranted.
\end{abstract}

Trial registration: This study was retrospectively registered at Chinese Clinical Trial Registry (ChiCTR-OPN-16008316, April 2016).

Keywords: Lung adenocarcinoma, Chemotherapy, Nedaplatin, Pemetrexed, Intensity-modulated radiotherapy

\footnotetext{
* Correspondence: yangwen3327@163.com

${ }^{\dagger}$ Equal contributors

'Department of Oncology, Nanhai Hospital of Southern Medical University,

Foshan 528200, China

Full list of author information is available at the end of the article
} 


\section{Background}

Approximately one third of all cancer-related deaths are due to lung cancer, which accounts for more deaths than breast, prostate, and colon cancer combined [1]. Non-small-cell lung cancer (NSCLC) accounts for approximately $80 \%$ of all cases of lung cancer [2]. Adenocarcinoma and squamous cell carcinoma are the two major subtypes of non-small cell lung carcinoma, with $\sim 70 \%$ of non-small cell lung carcinoma cases detected at an unresectable stage [3]. Lung adenocarcinoma is the most common type in females (smokers or nonsmokers) and non-smoking males; its percentage is higher in Asia than in North America [4]. Concurrent chemoradiotherapy is considered the standard of care for patients with inoperable stages II and III disease [5, 6]. Full-dose chemotherapy with concurrent chemoradiotherapy using a platinum-based third-generation (i.e. paclitaxel, vinorelbine, and docetaxel) doublet results in unacceptable toxicity [7]. Further studies to evaluate potential new chemotherapeutic agents that have radiosensitizing potential to pair with concurrent radiation, and can be used at full dose with thoracic radiotherapy (TRT) for the treatment of locally advanced non-small-cell lung cancer (LA-NSCLC) are necessary to improve efficacy [8]. Pemetrexed, an antifolate that inhibits multiple enzymes (thymidylate synthase, dihydrofolate reductase and glycinamide ribonucleotide formyl transferase) involved in purine and pyrimidine synthesis, has become a drug of choice for patients with lung adenocarcinoma $[9,10]$. Nedaplatin is a second-generation platinum derivative, which produces similar antitumor activities, but causes less nausea/vomiting and nephrotoxicity compared with cisplatin [11-14]. IMRT is an effective technique with acceptable acute toxicity, also when (sequentially or concomitantly) combined with chemotherapy [15]. Using IMRT to treat NSCLC leads to low rates of pulmonary and esophageal toxicity, and favorable clinical outcomes in terms of survival [16]. The combination of carboplatin/cisplatin, pemetrexed, and TRT may not be the optimal regimen for locally advanced patients. Therefore, a phase I study was designed to assess the feasibility of a combination of concurrent nedaplatin, pemetrexed and thoracic intensity-modulated, followed by nedaplatin/pemetrexed consolidation without the dose limiting toxicity (DLT) exceeding $33 \%$ in patients with inoperable Stage IIIA/B lung adenocarcinoma.

\section{Methods}

\section{Patient eligibility}

Patients with histologically or cytologically confirmed adenocarcinoma stage IIIA/IIIB, deemed unresectable by the Lung Cancer International Staging System, were eligible. Each patient was a candidate for definitive radiotherapy. Other eligibility criteria included the following: measurable or assessable disease as defined by the response evaluation criteria in solid tumours (RECIST) criteria, performance status (PS) of 0 or 1 , absolute neutrophil $\geq 2000$ cells $/ \mu \mathrm{L}$, and platelet count $\geq 100,000 / \mu \mathrm{L}$; hemoglobin level $\geq 9 \mathrm{~g} / \mathrm{dL}$; calculated creatinine clearance $\geq 60 \mathrm{~mL} / \mathrm{min}$; bilirubin level $\leq 2.0 \mathrm{mg} / \mathrm{dL}$; transaminase less than or equal to twice the upper limit of the normal value; forced expiratory volume in $1 \mathrm{~s}>1.0 \mathrm{~L}$. Exclusion criteria comprised previous surgery, radiation or chemotherapy; $>5 \%$ weight loss; clinically significant medical or psychiatric disorders. Bone scan and computed tomographic (CT) scans/magnetic resonance imaging of the chest, abdomen, and brain were performed. All patients provided written informed consent and the study was approved by the local ethics review board. This study was retrospectively registered at Chinese Clinical Trial Registry (ChiCTR-OPN-16008316, April 2016) after patient enrollment.

\section{Treatment}

The research protocol was approved by the ethics committee of the Nanhai Hospital of Southern Medical University. We also obtained the written consent of patients for participation. This study was designed to determine the possibility of administering concomitant pemetrexed/ nedaplatin chemotherapy and intensity-modulated radiotherapy followed by pemetrexed/nedaplatin consolidation chemotherapy for inoperable stage III lung adenocarcinoma without the DLT exceeding $33 \%$ in the patients. The secondary objectives included toxicity evaluation of concurrent chemoradiation, consolidation treatment, and complete treatment; assessment of response rate following concomitant treatment and at treatment completion; determination of overall and progression-free survival rates.

For chemotherapy, $500 \mathrm{mg} / \mathrm{m}^{2}$ Pemetrexed was administered i.v. on Days 1 and 22 in $250 \mathrm{~mL}$ normal saline throughout levels $1-3$, with premedication consisting of dexamethasone, folic acid and vitamin B12. Nedaplatin was administered by intravenous infusion for two concurrent cycles every 3 weeks. The dose of nedaplatin was escalated as follows: $60 \mathrm{mg} / \mathrm{m}^{2}$ (level 1), $70 \mathrm{mg} / \mathrm{m}^{2}$ (level 2), and $80 \mathrm{mg} / \mathrm{m}^{2}$ (level 3). Consolidation treatment consisted of three additional cycles of pemetrexed/nedaplatin $\left(500 \mathrm{mg} / \mathrm{m}^{2}, 60 \mathrm{mg} / \mathrm{m}^{2}\right.$ ) every 3 weeks after concurrent therapy.

In the case of radiotherapy, IMRT (intensity-modulated radiotherapy) was delivered to a cumulative dose of 6064 Gy at $2.0 \mathrm{~Gy} /$ fraction. Treatment planning was based on CT simulation. The gross target volume (GTV) included the primary tumor and involved lymph nodes. Involved field irradiation, omitting elective irradiation of lymph nodes, was used in order to optimize definitive dosing to the tumor [17]. A clinical target volume (CTV) was defined around the GTV and subclinical 
lymph node regions using an expansion of $0.5-1.0 \mathrm{~cm}$ for the presumed microscopic extension. A $0.7-0.8 \mathrm{~cm}$ margin was added to create an internal target volume (ITV). The planning target volume (PTV) consisted of ITV with the vertical field margins extended to $0.5-1.0 \mathrm{~cm}$ and lateral field margins extended to $0.5 \mathrm{~cm}$ for setup variations. Normal tissue constraints were as follows: the maximum point dose to the spinal cord, 48 Gy; total lung, V5 $<65 \%$ and V20<35\%; mean lung dose, $\leq 20$ Gy; heart, V30< $50 \%$. IMRT plans were developed by using a commercial treatment-planning system (XIO-Release 4.80, Elekta, Ltd., Stockholm, Sweden).

\section{Toxicity assessment and response}

Toxicity was assessed using the National Cancer Institute (NCI)'s Common Terminology Criteria for Adverse Events (CTCAE).v4.03 [18]. Assessment of disease response was carried out using the RECIST 1.1 criteria $[19,20]$ at 3 weeks after chemoradiation completion and a month after consolidation therapy. The best overall response is based on all tumor assessments starting from chemoradiation. Then, restaging scans were performed every 3 months for 1 year, and every 6 months from treatment end.

At least three patients were enrolled for each dose level, and had to have completed concurrent administration of nedaplatin/pemetrexed/radiotherapy without Dose-limiting toxicities (DLT) before escalation to the next dose. If 1 patient experienced DLT, 3 additional patients were accrued. If no more than 1 of the 6 patients experienced DLT, the next three patients were treated at the next higher dose level. If 2 out of 6 patients at a dose level experienced DLT, this level was considered the maximum tolerated dose (MTD). DLT were assessed during chemoradiation and up to 5 weeks after consolidation completion. Dose-limiting toxicities were defined from early and late toxicities as follows: Grade 3/4 hematological toxicity, febrile neutropenia, esophagitis, pneumonitis, or persistent elevation of creatinine, bilirubin and transaminase resulting in preventing treatment, or dosing delay because of toxicity (radiation therapy was delayed by a week or more; the following chemotherapy was delayed by 2 weeks or more, while consolidation therapy was delayed by 4 weeks or more after radiotherapy completion), or late high-grade $(>3)$ bronchopulmonary and esophageal toxicities according to criteria of the Radiation Therapy Oncology Group (RTOG).

\section{Statistical analyses}

Quantitative variables were described as median and standard deviation (SD). A potential follow-up of at least 24 months was required for analysis. Survival was defined as the time from the first day of treatment to death or last follow-up. Progression-free survival was measured from the first day of treatment to the time of disease progression. Overall and progression-free survival rates were estimated using the Kaplan-Meier method [21]. xStatistical analyses were performed using SPSS for Windows version 16.0.

\section{Results}

Between January 2012 and September 2013, 15 patients were enrolled in this study at the Nanhai Hospital of Southern Medical University and the Cancer Center of Guangzhou Medical University. The demographic characteristics of patients are shown in Table 1 .

At the Level 1 dose, 1 of the first 3 patients experienced grade 3 esophagitis and grade 2 neutropenia during the second cycle; because no DLT was observed at Level 1, nedaplatin dose was escalated to Level 2. One patient receiving Level 2 dose, with hepatitis B virus, developed viral hepatitis that resulted in grade 3 transaminase, and discontinued consolidation therapy after 2 concurrent chemotherapy cycles and full-dose radiation. More than $30 \%$ of patients developed grade $3 / 4$ neutropenia on Dose Level 3. One patient developed grade 4 thrombocytopenia and another experienced grade 3 pneumonitis that lasted at least a week, which were considered DLTs. Esophagus toxicity other than hematological toxicity was well tolerated. All patients completed irradiation (60-64Gy) as prescribed (Table 2). Delay of scheduled radiation therapy owing to esophagitis and pneumonitis occurred in only 2 patients (3 days and 1 week, respectively). The dose-volume histogram showed that the V20 and mean lung dose (MLD) of these patients

Table 1 Patient characteristics

\begin{tabular}{|c|c|c|c|c|}
\hline Characteristics & $\begin{array}{l}\text { Level } 1 \\
(N=3)\end{array}$ & $\begin{array}{l}\text { Level } 2 \\
(N=6)\end{array}$ & $\begin{array}{l}\text { Level } 3 \\
(N=6)\end{array}$ & N (\%) \\
\hline \multicolumn{5}{|l|}{ Age, y } \\
\hline Median (range) & $59(65-56)$ & $61(48-63)$ & $63(52-68)$ & $62(48-68)$ \\
\hline \multicolumn{5}{|l|}{ Gender, n } \\
\hline Male & 1 & 4 & 3 & $8(53 \%)$ \\
\hline Female & 2 & 2 & 3 & 7 (47 \%) \\
\hline \multicolumn{5}{|c|}{ ECOG performance status, $n$} \\
\hline 0 & 2 & 2 & 2 & $6(40 \%)$ \\
\hline 1 & 1 & 4 & 4 & $9(60 \%)$ \\
\hline \multicolumn{5}{|l|}{ Clinical stage } \\
\hline$\| I I$ & 1 & 2 & 2 & $5(33 \%)$ \\
\hline$\| \mathrm{B}$ & 2 & 4 & 4 & $10(67 \%)$ \\
\hline \multicolumn{5}{|l|}{ Smoking History, n } \\
\hline Never & 2 & 2 & 3 & $7(47 \%)$ \\
\hline Ever & 1 & 4 & 3 & $8(53 \%)$ \\
\hline Former & 1 & 2 & 1 & $4(27 \%)$ \\
\hline Current & 0 & 2 & 2 & $4(53 \%)$ \\
\hline
\end{tabular}


Table 2 Radiotherapy delivery

\begin{tabular}{|c|c|c|c|c|c|}
\hline \multirow{2}{*}{$\begin{array}{l}\text { Dose level } \\
\text { Level } 1\end{array}$} & \multirow{2}{*}{$\frac{N}{3}$} & \multicolumn{3}{|c|}{ Radiation therapy dose (Gy) } & \multirow{2}{*}{$\begin{array}{l}\text { Dose delay due to } \mathrm{AE} \\
1 \text { (3 days) }\end{array}$} \\
\hline & & 62 & $62^{\mathrm{a}}$ & 64 & \\
\hline \multirow[t]{2}{*}{ Level 2} & 6 & 64 & 60 & 62 & 0 \\
\hline & & 64 & 62 & 60 & \\
\hline \multirow[t]{2}{*}{ Level 3} & 6 & 60 & 64 & 62 & 1 (7 days) \\
\hline & & 64 & $60^{\mathrm{b}}$ & 62 & \\
\hline
\end{tabular}

${ }^{\mathrm{a}}$ Grade 3 esophagitis

${ }^{\mathrm{b}}$ Grade 3 pneumonitis

were 18-33\% and 926-1535 cGy, respectively. A total of 14 patients received consolidation therapy as planned. Table 3 summarizes the grade 3/4 adverse events observed during the chemoradiation and consolidation phases of the study. Severe late toxicities (radiation pneumonitis, prolonged esophagitis, or spinal cord toxicities) were uncommon in all longterm survivors.

In this study, response rates were $86.7 \%$ (95\% confidence interval [CI], 64.2-97.8\%) and $80.0 \%$ (95\% CI, 56.0-94.6\%) at chemoradiation end and treatment completion, respectively (Table 4). The median follow-up time for the censored cases was 26.3 months. The median OS was 30.0 months (95\% CI, 16.4 to 43.6 months), with a 3year OS rate of $44.0 \%$ (95\% CI, 18.7 to $69.2 \%$ ). The median PFS was 12.0 months (95\% CI, 6.9 to 17.0 months), with a 2-year PFS rate of $27.0 \%$ (95 \% CI, 4.7 to $49.3 \%$ ) (Figs. 1, 2). Only 2 patients had PD, which resulted from liver and contralateral lung metastases. DLTs were observed in one of six patients at level 2 , and two of six at level 3. The DLTs observed were grade 3 hepatitis and pneumonitis, and grade 4 thrombocytopenia. Dose-related grade 3 esophagitis, neutropenia, and vomiting were observed but were not dose-limiting. There was no late

Table 3 Grade 3-4 adverse events (CTCAE version 3.0, Concurrent chemoradiotherapy course $N=15$, Consolidation chemotherapy course $N=14$ )

\begin{tabular}{lll}
\hline Toxicity grade $3-4$ & $\begin{array}{l}\text { Concurrent } \\
\text { chemoradiotherapy N (\%) }\end{array}$ & $\begin{array}{l}\text { Consolidation } \\
\text { chemotherapy N (\%) }\end{array}$ \\
\hline Neutropenia & $5(33.3)$ & $2(14.3)$ \\
Anemia & $2(13.3)$ & $3(21.4)$ \\
Thrombocytopenia & $2(13.3)$ & $1(7.1)$ \\
Febrile & $1(6.7)$ & $0(0.0)$ \\
neutropenia & & $0(0.0)$ \\
Vomiting & $2(13.3)$ & $1(7.1)$ \\
Esophagitis & $3(20.0)$ & $0(0.0)$ \\
Transaminase & $1(6.7)$ & $0(0.0)$ \\
Pneumonitis & $1(6.7)$ & $0(0.0)$ \\
Creatinine & 0 &
\end{tabular}

Table 4 Efficacy (RECIST version 1.1)

\begin{tabular}{llll}
\hline Study phase & Response & N & $\%$ \\
\hline Chemoradiation & CR & 0 & 0.0 \\
& PR & 13 & 86.7 \\
& SD & 2 & 13.3 \\
Treatment completion & PD & 0 & 0.0 \\
& CR & 1 & 6.7 \\
& PR & 11 & 73.3 \\
& SD & 3 & 20.0 \\
& PD & 0 & 0 \\
\hline
\end{tabular}

$C R$ complete response, $P R$ partial response, $S D$ stable disease, $P D$ progressive disease

toxicity greater than grade 3 . The MTD was determined to be level 3 .

\section{Discussion}

A total of $30-40 \%$ of NSCLC patients present with locally or regionally advanced unresectable tumors. But the optimal regimen, dosage, and administered agents for locally-advanced non-small-cell lung cancer remain controversial. Radiation therapy (RT) combined with chemotherapy is more effective than RT alone, and concomitant chemoradiation has yielded improved survival compared to sequential chemotherapy and RT, but at the cost of heightened toxicity, especially esophagitis [22]. Current international guidelines recommend the use of platinum-based chemotherapy and concurrent thoracic radiotherapy (TRT) for patients with locally advanced non-small-cell lung cancer (NSCLC). Pemetrexed is considered to be less toxic than other cytotoxic agent. Previous studies have demonstrated that full dose pemetrexed-based chemotherapy concurrently with thoracic radiation therapy is feasible for NSCLC patients with unresectable stage III disease [23, 24]. We assessed the optimal dose, toxicity, and tolerability of concurrent dose-escalation of nedaplatin/pemetrexed with TRT followed by consolidation in patients with unresectable locally advanced lung adenocarcinoma.

Nedaplatin, a second-generation cisplatin analog and useful chemotherapeutic agent with radiosensitizing properties, has been developed to reduce cisplatin-induced toxicities, especially in patients with NSCLC, esophageal cancer, uterine cervical cancer, head and neck cancer, or urothelial cancer [25]. It was approved for the treatment of NSCLC, including adenocarcinoma and squamous carcinoma, in China. Teramoto et al. [12] reported a phase II study of docetaxel plus nedaplatin in patients with metastatic non-small-cell lung cancer. They found an overall response rate of $50.0 \%$; median survival and median progression-free survival times were 13.0 and 7.4 months, 
M S T : 30.0 months ( $95 \%$ CI, 16.4 to 43.6 )

2 -year survival rate: $44 \%(95 \%$ C I, 18.7 to 69.2$)$

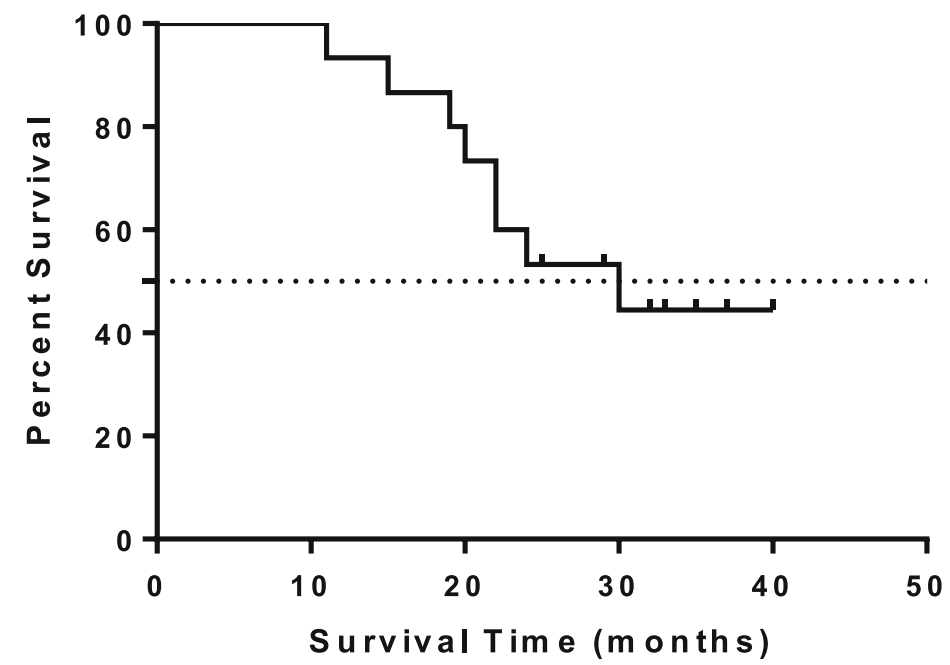

Fig. 1 Overall survival curve. MST, median survival time $(N=15)$

respectively. These findings indicate that the docetaxel and nedaplatin combination is well tolerated with potent activity in patients with metastatic NSCLC. Other phase II studies assessed nedaplatin in combination with irinotecan, gemcitabine and paclitaxel, respectively, used as firstline chemotherapy, and reported response rates of $65.8 \%$, $45.7 \%$ and $53.2 \%$, respectively, in patients with NSCLC [26-28]. In unresectable stage IIIA or IIIB NSCLC indicated for curative radiotherapy, Sekine et al. [29] reported a phase I study of nedaplatin at $80 \mathrm{mg} / \mathrm{m}^{2}$ and escalating doses of paclitaxel from 120 to $150 \mathrm{mg} / \mathrm{m}^{2}$ concurrently with thoracic radiotherapy (TRT) in 18 patients. It was concluded that paclitaxel and nedaplatin doses could not be escalated due to severe pulmonary toxicity at level 1 . Another phase I/II trial of weekly paclitaxel $\left(35 \mathrm{mg} / \mathrm{m}^{2}\right)$ and nedaplatin $\left(20 \mathrm{mg} / \mathrm{m}^{2}\right)$ for 6 weeks revealed that this regimen is safe and effective for NSCLC with concurrent TRT [30]. A phase II study led by Oshita et al. [31] evaluated a dose of nedaplatin at $50 \mathrm{mg} / \mathrm{m}^{2}$, and irinotecan at $60 \mathrm{mg} / \mathrm{m}^{2}$ on days 1 and 8 every 4 weeks for $2-4$ cycles with concurrent TRT ( 2 Gy per day, totaling 60 Gy). This treatment was effective and safe for patients, and 5-year disease-free and overall survival rates were $25.7 \%$ and $40.0 \%$, respectively. However, no Phase III study assessing

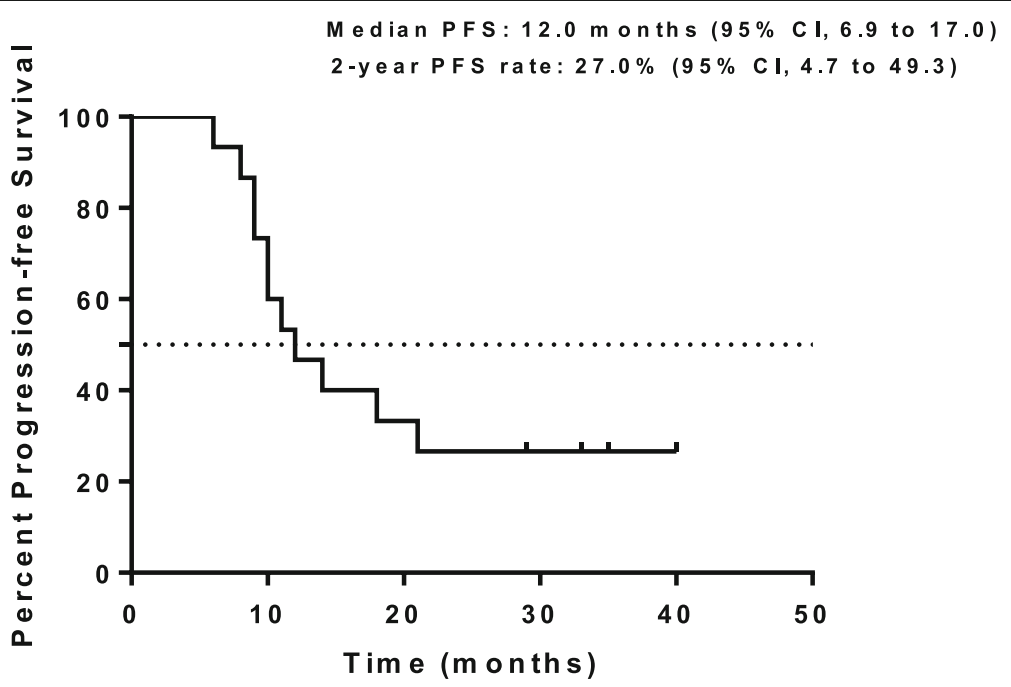

Fig. 2 Progression-free survival (PFS) curve $(N=15)$ 
chemotherapy or concurrent chemoradiotherapy using nedaplatin has been reported, because nedaplatin is not commonly used throughout the world.

Pemetrexed, a novel, multi-targeted antifolate chemotherapy agent that inhibits target enzymes (thymidylate synthase, dihydrofolate reductase, and glycinamide ribonucleotide formyl transferase), was initially approved for second-line treatment of advanced NSCLC [32]. Pemetrexed was subsequently approved as first-line in advanced non-squamous NSCLC based on a phase III trial showing a survival advantage for pemetrexed-cisplatin compared to gemcitabine-cisplatin [33]. Pemetrexed also is a feasible agent for concurrent chemoradiotherapy and consolidation therapy $[34,35]$.

Intensity-modulated radiotherapy (IMRT) is an advanced radiotherapy that uses intensity-modulated beams, which can provide multiple intensity levels for any single beam direction and a given source position, allowing shaped distributions and dose gradients with narrower margins than previously possible [36]. In comparison with 3D-CRT, involved-field radiotherapy (IF-RT) and IMRT combination leads to a significantly better sparing of normal tissues and higher total doses, while the potential therapeutic drawback of decreased incidental irradiation of elective lymph nodes is moderate [37].

Both agents have demonstrated safety and efficacy in locally advanced non-small cell lung cancer in conjunction with Radiation therapy.

On the definition of Dose-limiting toxicities, there are some difference among them because of the various methods and theories. In most cases, DLTs were defined as severe toxicity leading to dose reduction or treatment discontinuation [38-40]. According to the criteria for DLT in the protocol, we determine The MTD to be level 3 (nedaplatin $80 \mathrm{mg} / \mathrm{m}^{2}$ ) in this trial. The recommended dose is to be the best tolerated dose immediately below the MTD [41]. In the majority of the trials, the recommended dose was usually defined as one dose level below the MTD. But in some trials the recommended dose was equivalent to the MTD. There was lack of standardization, so we recommend the lower dose for safety. This study identified the recommended nedaplatin dose at $70 \mathrm{mg} / \mathrm{m}^{2}$ for phase II evaluation. The dose of chemotherapy in current study was lower than that in a Japanese phase III study of $100 \mathrm{mg} / \mathrm{m}^{2}$ nedaplatin and $60 \mathrm{mg} / \mathrm{m}^{2}$ docetaxel, or $80 \mathrm{mg} / \mathrm{m}^{2}$ cisplatin and $60 \mathrm{mg} /$ $\mathrm{m}^{2}$ docetaxel for squamous cell lung cancer with stage IIIB/IV or postoperative recurrence [42]. They showed that OS (13.6 vs 11.4 months) was significantly longer in the nedaplatin group, but grade 3 or worse leucopenia (55\% vs $45 \%$ ), neutropenia (82\% vs $71 \%$ ), and thrombocytopenia (9 \% vs $0 \%$ ) were more frequent in the nedaplatin group. Toxicity were more serious compare to the outcome of this study. To avoid severe adverse effects and interruption of radiationtherapy, appropriate dose reduction would be feasible. Indeed, the comparatively small sample size and short follow-up time in the current investigation present limitations. Future studies are warranted.

The response group was defined as patients achieving a CR or PR. In the chemoradiation phase and treatment completion, the response rate was $86.7 \%$ and $80.0 \%$, respectively. The majority of patients experienced PR (thirteen patients) and two patients had SD in chemoradiation phase. At completion of treatment three patients had SD, in addition, one patient obtained CR and thirteen patients PR as their best overall tumour response. Further more, two of the three patients had SD for at least 6 months. The median OS was 30.0 months with a 3 -year OS rate of $44.0 \%$. The median PFS was 12.0 months with a 2-year PFS rate of $27.0 \%$. Our results are consistent with previous studies. A phase I study of pemetrexed plus cisplatin followed by pemetrexed consolidation therapy with dose-escalation of TRT in patients with locally advanced nonsquamous NSCLC showed that the objective response rate was $83 \%$. A phase II study of pemetrexed plus cisplatin with concurrent TRT in Stage IIIA or Stage IIIB nonsquamous NSCLC showed a best overall response of $72 \%$ (PFS, 13.8 months; OS, 26.2 months) [43]. Furthermore, a randomized phase III study was performed to investigate the effect of pemetrexed $500 \mathrm{mg} / \mathrm{m}^{2}+$ cisplatin $75 \mathrm{mg} / \mathrm{m}^{2}$ or etoposide $50 \mathrm{mg} / \mathrm{m}^{2}+$ cisplatin $50 \mathrm{mg} / \mathrm{m}^{2}$ with plus concurrent TRT followed by pemetrexed consolidation cytotoxic chemotherapy in locally advanced nonsquamous NSCLC [44]. It shows that median PFS, ORR and disease control rate was respectively 11.4 months, $35.9 \%$ and $80.7 \%$ in the pemetrexedcisplatin group and 9.8 months, $33.0 \%$ and $70.7 \%$ in the etoposide-cisplatin group. The Pem + Cis arm did not improve PFS compared with the control arm, but had a greater security.

\section{Conclusions}

In conclusion, the present phase I study is the first of its kind assessing combination therapy by nedaplatin and pemetrexed with thoracic intensity-modulated radiotherapy for inoperable stage III lung adenocarcinoma. The DLTs seen with this combination were hepatitis, thrombocytopenia, febrile neutropenia, and pulmonary toxicity. Preliminary local disease control and overall survival are encouraging. Our findings suggest that full dose $500 \mathrm{mg} / \mathrm{m}^{2}$ of pemetrexed and nedaplatin $70 \mathrm{mg} / \mathrm{m}^{2}$ could be used safely with thoracic intensity-modulated radiotherapy for inoperable stage III lung adenocarcinoma.. The response rate, PFS, and overall survival are encouraging. An ongoing phase II/III study is to evaluate the efficacy of the same chemoradiation platform as the 
present trial or cisplatin and pemetrexed in patients with unresectable stage III lung adenocarcinoma. Further evaluation of stage III lung adenocarcinoma management is required.

\begin{abstract}
Abbreviations
Cl: Confidence interval; CR: Complete response; CT: Computed tomography; CTCAE: National cancer institute (NCl)'s common terminology criteria for adverse events; CTV: Clinical target volume; DLT: Dose limiting toxicity; GTV: Gross target volume; IF-RT: Involved-field radiotherapy; ITV: Interna target volume; LA-NSCLC: Locally advanced non-small-cell lung cancer; MRI: Magnetic resonance imaging; MST: Median survival time; MTD: Maximum-tolerated dose; NSCLC: Non-small-cell lung cancer; OS: Overall survival; PD: Progressive disease; PFS: Progression-free survival; PR: Partial response; PS: Performance status; PTV: Planning target volume; RECIST: Response evaluation criteria in solid tumors; RT: Radiation therapy RTOG: Radiation therapy oncology group; SD: Stable disease; TRT: Thoracic radiotherapy
\end{abstract}

\section{Acknowledgments}

Not applicable.

\section{Funding}

This work was supported by the Funds of Medical Scientific Technological Department-Funded Research Projects, Foshan City, Guangdong Province, China under Contract No. (2015AB000572).

\section{Availability of data and materia}

Dataset (s) supporting this trial will be presented within the manuscript when the study is complete.

\section{Authors' contributions}

LYY, and YW were involved in the conception and design of the study. DJ was involved in the provision of study material and patients. GWG and YH performed the data analysis and interpretation. LYY and GWG wrote the manuscript. YW approved the final version. All authors read and approved the final manuscript

\section{Competing interests}

The authors declare that they have no competing interests.

\section{Consent for publication}

Not applicable.

\section{Ethics approval and consent to participate}

This study was approved by the ethics committee of the Nanhai Hospital of Southern Medical University. Patients who participated and whose data is presented in the study have provided written informed consent for the use of their data.

\section{Author details}

'Department of Oncology, Nanhai Hospital of Southern Medical University, Foshan 528200, China. ${ }^{2}$ Department of Radiotherapy, Cancer Center of Guangzhou Medical University, Guangzhou 510000, China.

\section{Received: 18 November 2015 Accepted: 22 September 2016} Published online: 07 October 2016

\section{References}

1. Siegel RL, Miller KD, Jemal A. Cancer statistics, 2015. CA Cancer J Clin. 2015;65(1):5-29.

2. Peters S, Adjei A, Gridelli C, Reck M, Kerr K, Felip E, Group EGW. Metastatic non-small-cell lung cancer (NSCLC): ESMO Clinical Practice Guidelines for diagnosis, treatment and follow-up. Ann Oncol. 2012;23(7):vii56-64.

3. Rekhtman N, Ang DC, Sima CS, Travis WD, Moreira AL. Immunohistochemical algorithm for differentiation of lung adenocarcinoma and squamous cell carcinoma based on large series of whole-tissue sections with validation in small specimens. Mod Pathol. 2011;24(10):1348-59.
4. Charloux A, Quoix E, Wolkove N, Small D, Pauli G, Kreisman H. The increasing incidence of lung adenocarcinoma: reality or artefact? A review of the epidemiology of lung adenocarcinoma. Int J Epidemiol. 1997;26(1):14-23.

5. Aupérin A, Le Péchoux C, Rolland E, Curran WJ, Furuse K, Fournel P, Belderbos J, Clamon G, Ulutin HC, Paulus R. Meta-analysis of concomitant versus sequential radiochemotherapy in locally advanced non-small-cell lung cancer. J Clin Oncol. 2010;28(13):2181-90.

6. O'Rourke N, Roqué I, Figuls M, Farré Bernadó N, Macbeth F. Concurrent chemoradiotherapy in non-small cell lung cancer. Cochrane Database Syst Rev. 2010;6:CD002140.

7. Hida N, Okamoto H, Misumi Y, Sato A, Ishii M, Kashizaki F, Shimokawa T, Shimizu T, Watanabe K. A phase I trial of concurrent chemoradiotherapy with non-split administration of docetaxel and cisplatin for dry stage III non-small-cell lung cancer (JCOG9901DI). Cancer Chemother Pharmacol. 2012;69(6):1625-31.

8. Niho S, Kubota K, Nihei K, Sekine I, Sumi M, Sekiguchi R, Funai J, Enatsu S, Ohe Y, Tamura T. Dose-Escalation Study of Thoracic Radiotherapy in Combination With Pemetrexed Plus Cisplatin Followed by Pemetrexed Consolidation Therapy in Japanese Patients With Locally Advanced Nonsquamous NonSmall-Cell Lung Cancer. Clin Lung Cancer. 2013;14(1):62-9.

9. Sequist LV, Yang JC-H, Yamamoto N, O'Byrne K, Hirsh V, Mok T, Geater SL, Orlov S, Tsai C-M, Boyer M. Phase III study of afatinib or cisplatin plus pemetrexed in patients with metastatic lung adenocarcinoma with EGFR mutations. J Clin Oncol. 2013;31(27):3327-34.

10. Scagliotti G, Hanna N, Fossella F, Sugarman K, Blatter J, Peterson P, Simms L, Shepherd FA. The differential efficacy of pemetrexed according to NSCLC histology: a review of two Phase III studies. Oncologist. 2009;14(3):253-63.

11. Furuse K, Fukuoka M, Kurita K, Ariyoshi Y, Niitani H, Yoneda S, Fujii M, Hasegawa K, Nishiwaki Y, Tamura M. A phase II study of cis-diammine glycolato platinum, 254-S, for primary lung cancer. Jpn J Cancer Chemother. 1992;19:874.

12. Teramoto K, Asada Y, Ozaki Y, Suzumura Y, Nakano Y, Sawai S, Tezuka N, Inoue S, Fujino S. A phase II study of docetaxel plus nedaplatin in patients with metastatic non-small-cell lung cancer. Cancer Chemother Pharmacol. 2012;70(4):531-7.

13. Kurata T, Tamura K, Yamamoto N, Nogami T, Satoh T, Kaneda H, Nakagawa K, Fukuoka M. Combination phase I study of nedaplatin and gemcitabine for advanced non-small-cell lung cancer. Br J Cancer. 2004;90(11):2092-6.

14. Ota K. Nedaplatin. Gan to kagaku ryoho Cancer \& chemotherapy. 1996; 23(3):379-87.

15. Govaert SL, Troost EG, Schuurbiers OC, De Geus-Oei L-F, Termeer A, Span PN, Bussink J. Treatment outcome and toxicity of intensity-modulated (chemo) radiotherapy in stage III non-small cell lung cancer patients. Radiat Oncol. 2012;7(1):1.

16. Jiang Z-Q, Yang K, Komaki R, Wei X, Tucker SL, Zhuang Y, Martel MK, Vedam S, Balter P, Zhu G. Long-term clinical outcome of intensity-modulated radiotherapy for inoperable non-small cell lung cancer: the MD Anderson experience. Int J Radiat Oncol Biol Phys. 2012;83(1):332-9.

17. Yuan S, Sun X, Li M, Yu J, Ren R, Yu Y, Li J, Liu X, Wang R, Li B. A randomized study of involved-field irradiation versus elective nodal irradiation in combination with concurrent chemotherapy for inoperable stage III nonsmall cell lung cancer. Am J Clin Oncol. 2007;30(3):239-44.

18. Health UDo, Services H. Common Terminology Criteria for Adverse Events (CTCAE) Version 4.03. 2010. Washington: US Government Publishing Office; 2015.

19. Nishino M, Jackman DM, Hatabu H, Yeap BY, Cioffredi L-A, Yap JT, Jänne PA, Johnson BE, Van den Abbeele AD. New Response Evaluation Criteria in Solid Tumors (RECIST) Guidelines for Advanced Non-Small Cell Lung Cancer: Comparison with Original RECIST and Impact on Assessment of Tumor Response to Targeted Therapy. AJR Am J Roentgenol. 2010; 195(3):W221.

20. Eisenhauer E, Therasse P, Bogaerts J, Schwartz L, Sargent D, Ford R, Dancey J, Arbuck S, Gwyther S, Mooney M. New response evaluation criteria in solid tumours: revised RECIST guideline (version 1.1). Eur J Cancer. 2009;45(2):228-47

21. Kaplan EL, Meier P. Nonparametric estimation from incomplete observations. J Am Stat Assoc. 1958;53(282):457-81.

22. Langer CJ. Novel Cytotoxic Agents in Combination with Radiation in the Management of Locally Advanced Non-Small Cell Lung Cancer: Focus on Pemetrexed and Nab-Paclitaxel [Abraxane]. In: Advances in Radiation Oncology in Lung Cancer. Heidelberg: Springer; 2011. p. 765-71.

23. Choy H, Gerber DE, Bradley JD, lyengar P, Monberg M, Treat J, Govindan R, Koustensis A, Barker S, Obasaju C. Concurrent pemetrexed and radiation 
therapy in the treatment of patients with inoperable stage III non-small cell lung cancer: a systematic review of completed and ongoing studies. Lung Cancer. 2015;87(3):232-40.

24. Zhang Q, Cai X-W, Zhu Z-F, Yu W, Liu Q, Feng W, Xue M-C, Fu X-L. Full-dose pemetrexed plus cisplatin combined with concurrent thoracic radiotherapy for previously untreated advanced nonsquamous non-small cell lung cancer. Anti-Cancer Drugs. 2015;26(4):456-63.

25. Shimada $M$, Itamochi $H$, Kigawa J. Nedaplatin: a cisplatin derivative in cancer chemotherapy. Cancer Manag Res. 2013;5:67-76.

26. Oshita F, Yamada K, Saito H, Noda K, Hamanaka N, Ikehara M. Phase II study of nedaplatin and irinotecan for elderly patients with advanced non-small cell lung cancer. J Exp Ther Oncol. 2004;4:343-8.

27. Sugiyama T, Hirose T, Nakashima M, Ishida K, Oki Y, Murata Y, Kusumoto S, Shirai T, Yamaoka T, Okuda K. Evaluation of the efficacy and safety of the combination of gemcitabine and nedaplatin for elderly patients with advanced non-small-cell lung cancer. Oncology. 2011;81(3-4):273-80.

28. Hirose T, Sugiyama T, Kusumoto S, Shirai T, Nakashima M, Yamaoka T, Okuda K, Ogura K, Ohnishi T, Ohmori T. Phase II study of the combination of nedaplatin and weekly paclitaxel in patients with advanced non-small cell lung cancer. Anticancer Res. 2009;29(5):1733-8.

29. Sekine I, Sumi M, Ito Y, Kato T, Fujisaka Y, Nokihara H, Yamamoto N, Kunitoh $H$, Ohe $Y$, Tamura T. Phase I study of cisplatin analogue nedaplatin, paclitaxel, and thoracic radiotherapy for unresectable stage III non-small cell lung cancer. Jpn J Clin Oncol. 2007;37(3):175-80.

30. Hasegawa Y, Takanashi S, Okudera K, Aoki M, Basaki K, Kondo H, Takahata T, Yasui-Furukori N, Tateishi T, Abe Y. Weekly paclitaxel and nedaplatin with concurrent radiotherapy for locally advanced non-small-cell lung cancer: a phase I/II study. Jpn J Clin Oncol. 2004;34(11):647-53.

31. Oshita F, Ohe M, Honda T, Murakami S, Kondo T, Saito H, Noda K, Yamashita K, Nakayama Y, Yamada K. Phase II study of nedaplatin and irinotecan with concurrent thoracic radiotherapy in patients with locally advanced nonsmall-cell lung cancer. Br J Cancer. 2010;103(9):1325-30.

32. Hanna N, Shepherd FA, Fossella FV, Pereira JR, De Marinis F, Von Pawel J, Gatzemeier U, Tsao TCY, Pless M, Muller T. Randomized phase III trial of pemetrexed versus docetaxel in patients with non-small-cell lung cancer previously treated with chemotherapy. J Clin Oncol. 2004;22(9):1589-97.

33. Scagliotti GV, Parikh P, Von Pawel J, Biesma B, Vansteenkiste J, Manegold C, Serwatowski P, Gatzemeier U, Digumarti R, Zukin M. Phase III study comparing cisplatin plus gemcitabine with cisplatin plus pemetrexed in chemotherapy-naive patients with advanced-stage non-small-cell lung cancer. J Clin Oncol. 2008;26(21):3543-51.

34. Govindan R, Bogart J, Stinchcombe T, Wang X, Hodgson L, Kratzke R, Garst J, Brotherton T, Vokes EE. Randomized phase II study of pemetrexed, carboplatin, and thoracic radiation with or without cetuximab in patients with locally advanced unresectable non-small-cell lung cancer: Cancer and Leukemia Group B trial 30407. J Clin Oncol. 2011;29(23):3120-5.

35. Vokes EE, Senan S, Treat JA, Iscoe NA. PROCLAIM: A phase III study of pemetrexed, cisplatin, and radiation therapy followed by consolidation pemetrexed versus etoposide, cisplatin, and radiation therapy followed by consolidation cytotoxic chemotherapy of choice in locally advanced stage III non-small-cell lung cancer of other than predominantly squamous cell histology. Clin Lung Cancer. 2009;10(3):193-8.

36. Bezjak A, Rumble R, Rodrigues G, Hope A, Warde P, Panel IIE. Intensity-modulated radiotherapy in the treatment of lung cancer. Clin Oncol. 2012;24(7):508-20.

37. Fleckenstein J, Eschler A, Kremp K, Kremp S, Rübe C. Dose distribution and tumor control probability in out-of-field lymph node stations in intensity modulated radiotherapy (IMRT) vs 3D-conformal radiotherapy (3D-CRT) of non-small-cell lung cancer: an in silico analysis. Radiat Oncol. 2015;10(1):1.

38. Advani RH, Buggy JJ, Sharman JP, Smith SM, Boyd TE, Grant B, Kolibaba KS, Furman RR, Rodriguez S, Chang BY. Bruton tyrosine kinase inhibitor ibrutinib (PCl-32765) has significant activity in patients with relapsed/refractory B-cell malignancies. J Clin Oncol. 2013;31(1):88-94.

39. Huillard O, Mir O, Peyromaure M, Tlemsani C, Giroux J, Boudou-Rouquette $P$, Ropert S, Delongchamps NB, Zerbib M, Goldwasser F. Sarcopenia and body mass index predict sunitinib-induced early dose-limiting toxicities in renal cancer patients. Br J Cancer. 2013;108(5):1034-41.

40. Cardenal F, Arnaiz MD, Morán T, Jové J, Nadal E, Porta R, Solé JM, Brao I, Palmero R, Fuentes R. Phase I study of concurrent chemoradiation with pemetrexed and cisplatin followed by consolidation pemetrexed for patients with unresectable stage III non-small cell lung cancer. Lung Cancer. 2011;74(1):69-74.
41. Seymour LW, Ferry DR, Anderson D, Hesslewood S, Julyan PJ, Poyner R, Doran J, Young AM, Burtles S, Kerr DJ. Hepatic drug targeting: phase I evaluation of polymer-bound doxorubicin. J Clin Oncol. 2002;20(6):1668-76.

42. Shukuya T, Yamanaka T, Seto T, Daga H, Goto K, Saka H, Sugawara S, Takahashi T, Yokota S, Kaneda H. Nedaplatin plus docetaxel versus cisplatin plus docetaxel for advanced or relapsed squamous cell carcinoma of the lung (WJOG5208L): a randomised, open-label, phase 3 trial. Lancet Oncol. 2015;16(16):1630-8.

43. Garrido P, Engel-Riedel W, Serke M, Giraud P, Ricardi U, Vallejo C, Visseren-Grul C, Ameryckx S, Soldatenkova V, Chouaki N. Final results from a Phase II study of pemetrexed and cisplatin with concurrent thoracic radiation after Pem-Cis induction in patients with unresectable locally advanced non-squamous non-small cell lung cancer (NSCLC). Lung Cancer. 2015;88(2):160-6.

44. Senan S, Brade A, Wang LH, Vansteenkiste J, Dakhil S, Biesma B, Aguillo MM, Aerts J, Govindan R, Rubio-Viqueira B. PROCLAIM: Randomized Phase III Trial of Pemetrexed-Cisplatin or Etoposide-Cisplatin Plus Thoracic Radiation Therapy Followed by Consolidation Chemotherapy in Locally Advanced Nonsquamous Non-Small-Cell Lung Cancer. J Clin Oncol. 2016;34(9):953-62.

\section{Submit your next manuscript to BioMed Central and we will help you at every step:}

- We accept pre-submission inquiries

- Our selector tool helps you to find the most relevant journal

- We provide round the clock customer support

- Convenient online submission

- Thorough peer review

- Inclusion in PubMed and all major indexing services

- Maximum visibility for your research

Submit your manuscript at www.biomedcentral.com/submit
C Biomed Central 